\title{
Translation and Cross-Cultural Adaptation of the Manchester Orofacial Pain Disability Scale
}

\author{
Monira Samaan Kallás ${ }^{1}$, Edgard Michel Crosato ${ }^{1}$, Maria Gabriela Haye Biazevic ${ }^{1}$, Matsuyoshi \\ Mori $^{2}$, Vishal R. Aggarwal ${ }^{3}$ \\ ${ }^{1}$ Department of Community Dentistry, School of Dentistry, University of São Paulo, Brazil. \\ ${ }^{2}$ Department of Dental Prosthesis, School of Dentistry, University of São Paulo, Brazil. \\ ${ }^{3}$ School of Dentistry, Manchester Biomedical Research Centre, University of Manchester, United Kingdom.
}

\author{
Corresponding Author: \\ Monira Samaan Kallás \\ Av. Paulista 960 ap 702, Bela Vista - 01310-100, São Paulo-SP \\ Brazil \\ Phone: +5511998817525 \\ E-mail: monira@usp.br
}

\begin{abstract}
Objectives: The purpose of the present study was to translate and perform a cross-cultural adaptation of Manchester Orofacial Pain Disability Scale to the Portuguese language.

Material and Methods: A synthesis of two independent translations done by bilingual translators whose mother tongue was the Portuguese language began the process of translation. From the synthesis of the translated version and totally blind to the original version, two different non-native English language teachers without dental knowledge translated the questionnaire back to English. The pre-final version was done by an Expert committee: the researchers, two other nonnative English language teachers and one native English language speaker. The new questionnaire was then piloted among 8 patients from the target setting that were interviewed to probe it on their perceived meaning of each question. The Manchester Orofacial Pain Disability Scale (MOPDS) thus translated was called Brasil-MOPDS and was validated in 50 patients with Orofacial pain from TMJ and Occlusion clinic ambulatory of São Paulo University School of Dentistry. The Brasil-MOPDS was administered twice by an interviewer (15 - 20 day interval) and once by a second independent interviewer. The Brazilian version of the short form oral health impact profile (OHIP-14) questionnaire and the visual analogue pain scale (VAS) were applied on the same day.

Results: Internal consistency (Cronbach's $\alpha=0.9)$, inter-observer $(\mathrm{ICC}=0.92)$ and intra-observer $(\mathrm{ICC}=0.98)$ correlations presented high scores. Validity of Brasil-MOPDS compared to OHIP-14 ( $\mathrm{r}=0.85)$ and VAS $(\mathrm{r}=0.75)$ shown high correlations. Conclusions: Brasil-MOPDS was successfully translated and adapted to be applied to Brazilian patients, with satisfactory internal and external reliability.
\end{abstract}

Keywords: orofacial pain; oral health; quality of life; visual analogue pain scale.

Accepted for publication: 21 August 2012.

To cite this article:

Kallás MS, Crosato EM, Maria Biazevic MG, Mori M, Aggarwal VR. Translation and Cross-Cultural Adaptation of the Manchester Orofacial Pain Disability Scale.

J Oral Maxillofac Res 2012;3(4):e3

URL: http://www.ejomr.org/JOMR/archives/2012/4/e3/v3n4e3ht.pdf

doi: $10.5037 /$ jomr.2012.3403 


\section{INTRODUCTION}

Pain affects all aspects of a person's life including sleep, work, leisure and relationships. It impacts on the lives of sufferers by causing limitations in daily life and this in turn imposes a huge burden on society, due to the high direct costs of treatment and indirect costs from lost productivity [1-4].

Pain is a personal, subjective experience. Approaches to the measurement of pain include verbal and numeric self-rating scales, behavioural observation scales, and physiologic responses. Because of complex nature of the experience of pain and its subjective characteristic, patients' self-reports provide the most valid measure [5]. Orofacial pain has a variety of consequences on physical and psychosocial functions []. Self-reported measures of oral health quality of life relate altered functions and symptoms to social and psychological wellbeing. However, different oral conditions may affect functioning and physical and emotional problems in different ways and therefore disease specific instruments may be invaluable in investigating the impact of these conditions on individuals.

Brazilian studies about disabilities caused by orofacial pain use RDC/TMD (Research Diagnostic Criteria for Temporomandibular Disorders) Axis II, OIDP (Oral Impact Daily Performance), OHIP (Oral Health Impact Profile), GHQ-12 (General Health Questionnaire) and Brazilian version of McGill Pain Questionnaire. Although these tools were not specifically developed to assess orofacial pain related disability, they all concluded that oro-facial pain imposes a huge burden on the daily life of sufferers [7-9].

The Manchester Orofacial Pain Disability Scale (MOPDS) construction and validation has been previously demonstrated. This tool has been shown to be robust in measuring orofacial pain related disability and had good construct validity [10].

With the increasing number of international research projects, the need to adapt measures of health status to use the language of origin has grown rapidly. Most questionnaires were developed in English-speaking countries, but even within those countries, researchers should consider translating these for immigrants, especially when their exclusion may lead to systematic bias in studies of health care related quality of life. Thus Beaton et al. [11] recommend cross-cultural adaptation in addition to simple translation for questionnaires of health status that are going to be used in a different language and culture from which they were originally developed.

This paper therefore aims to adapt the Manchester Orofacial Pain Disability Scale to a Portuguese language version through a formal translation/backtranslation process and summarize available data about its psychometric properties.

Specific objectives were to determine the internal consistency and reliability of the translated scale and to validate its use for measuring orofacial pain specific disability in Brazilian patients.

\section{MATERIAL AND METHODS}

The guidelines for translation and cross-cultural adaptation process (Beaton et al. [11] and Wild et al. [12] were used following the stages above:

\section{Stage I: Initial Translation}

Two independent translations from English to Portuguese were made by two bilingual translators whose mother tongue is the Portuguese language in order to accurately reflect the nuances of the language. Both translators had different profiles or backgrounds one with academic vinculum (with theme knowledge) and the second one a clinical dentist.

\section{Stage II: Synthesis of the Translations}

A synthesis of these translations was first conducted (producing one common translation) by the authors of the research and two non-native English language teachers.

\section{Stage III: Back Translation}

Working from the synthesis of the translated versions and totally blind to the original version, two different non-native English language teachers without dental knowledge translated the questionnaire back to the English language.

\section{Stage IV: Expert Committee}

An Expert committee reviewed the pre-final version: the researchers, two other non-native English language teachers and one native English speaking professor.

\section{Stage V: Test of the Prefinal Version}

This field test of the new questionnaire was used in 8 patients from the target setting. Each subject completed the questionnaire and was interviewed to probe what he or she believed to be the meaning of each questionnaire item and its response. In this stage these patients suggested to exclude the question "I am irritable, angry and easily frustrated", justifying that its items are repeated in other questions. The second question suggested to exclude was "I have lost earnings" because its semantic equivalence with the item "I have had to take time off work". 
Stage VI: Submission of Documentation to the Coordinating Committee for Appraisal of the Adaptation Process

The final stage in the adaptation process was the submission of all the reports to a committee formed by the authors of the research and another Portuguese speaking professor. As related in the item above this committee decided to remove the questions "I am irritable, angry and easily frustrated "and "I have lost earnings".

The Brazil-MOPDS was applied in fifty patients with symptoms of orofacial pain who consulted at the TMJ and Occlusion clinic of the Prosthetic Department of São Paulo University School of Dentistry, Brazil. All patients were recruited before any type of treatment, clinical consultation or other information about orofacial pain was collected and all of approached patients agreed to participate. Initially they were 75 but only 50 concluded the steps of the designed study (Figure 1). VAS and OHIP-14 were applied to evaluate validity of Brazil-MOPDS. The Brasil-MOPDS was administered twice by an interviewer (15 - 20 day interval) and once by a second independent interviewer. The Brazilian version of the short form oral health impact profile (OHIP-14) questionnaire and the visual analogue scale (VAS) were applied on the same day.

OHIP-14 score were based on its seven dimensions (physiological discomfort, pain, physiologic inability, physical inability, function limitation, disability and social inability) and scored from 0 - 4 based on a Likert scale: 0 - never, 1 - rarely, 2 - sometimes, 3 - frequently and 4 - always. This value was then multiplied by the weight of each question to give a score ranging from 0 (less oral health impact on daily profile) to 28 points (more impact) [1] .

All participants have read and signed informed consent form. The use of human subjects in this study has been reviewed and approved by University of São Paulo Dentistry School Ethics Committee. This study was conduced from August 1, 2008 to March 1, 2009).

\section{Statistical analysis}

Data were tabulated and analyzed in STATA 10 [14] and for all tests it were used Confidence Interval of $95 \%$. Internal consistency was examined by Cronbach $\alpha$. In order to find the correlation between each question and the overall outcome of the test, the Spearman Correlation Coefficient (SCC) was performed, using data from the first interview (main test). Psychometric Properties: reliability was estimated by assessing the internal consistency (indicated by Cronbach $\alpha$ ) and reproducibility (test-retest). The statistical value of Cronbach $\alpha$ was also calculated for each excluded question from the Brazil-MOPDS as the objective of statistical investigation was to numerically represent the interests of uniformity or trend in the responses within each item of the questionnaire.

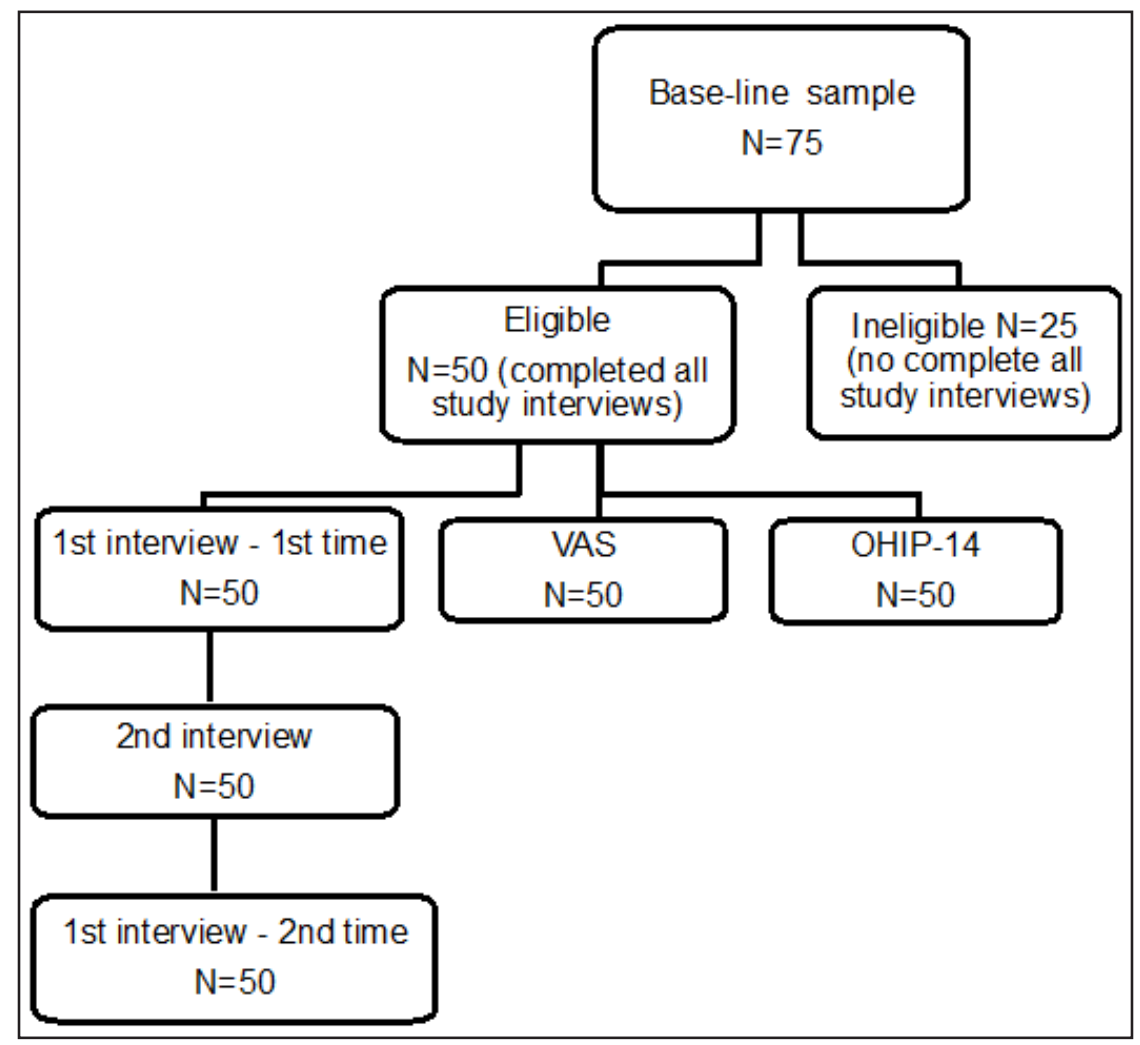

Figure 1. Study design. 
Reliability was checked by the application of BrazilMOPDS on two occasions by the same rater, called internal reliability. External reliability was the comparison of the answers obtained by the first and the second evaluator. For these analysis interclass correlation coefficient (ICC) and Bland-Altman test [15] were used.

\section{RESULTS}

The samples were distributed by gender and age. Most of the participants were women $(86 \%)$ with the average age of 40.7 (SD 14.03) years old (Table 1).

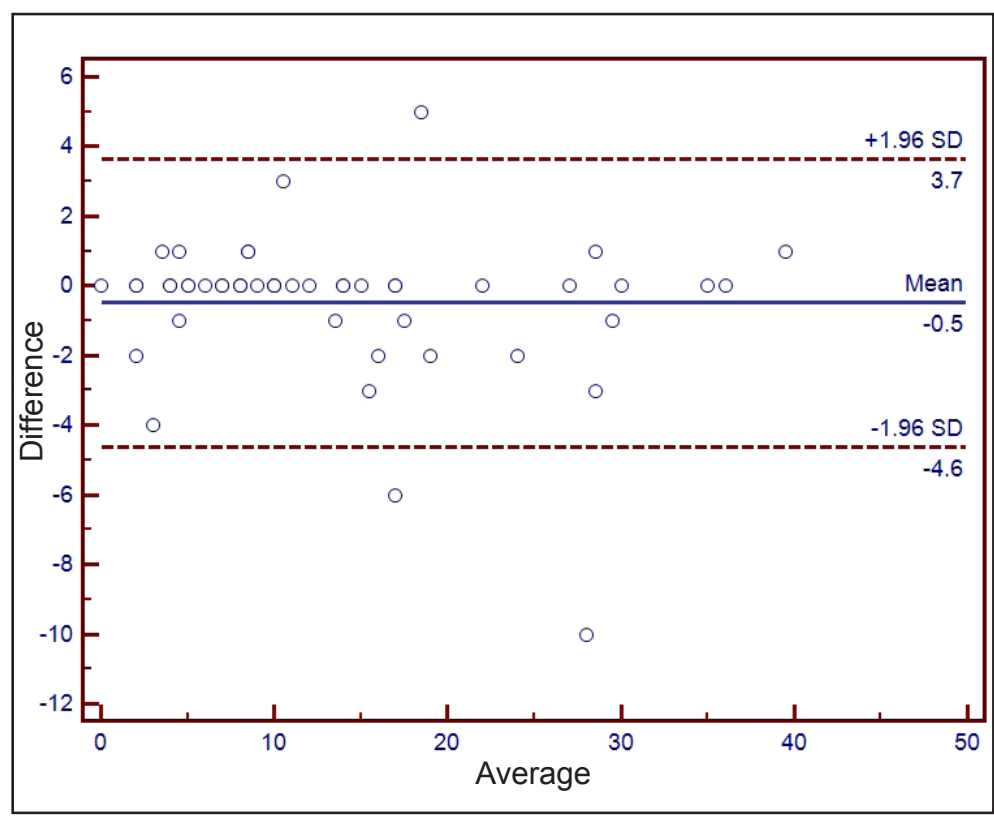

Figure 2. Bland-Altman Plot with inter observer reproducibility.

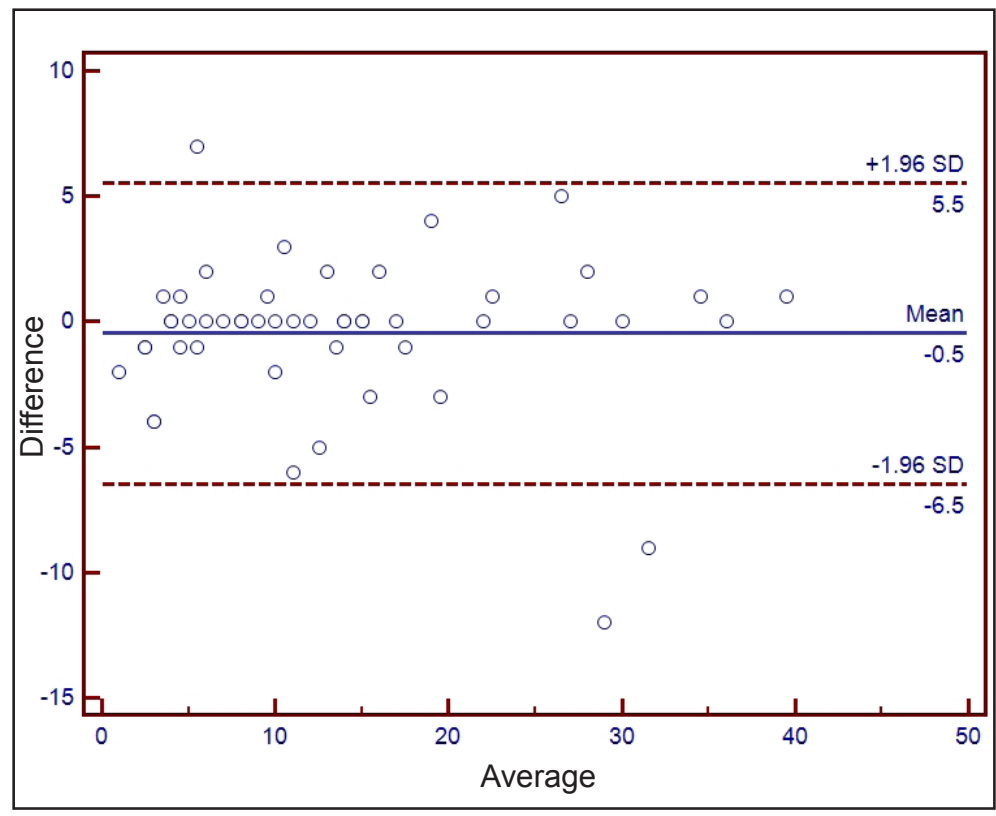

Figure 3. Bland-Altman Plot with intra observer reproducibility.
The answers of the questionnaire obtained by the first rate (first and second interview) and the second rate are described in Table 2. The correlation between each question, the whole result and Cronbach $\alpha$ is shown in Table 3.

Reproducibility (test-retest): interobserver correlation data obtained in questionnaire administration indicated an excellent agreement with ICC $=0.924$ (CI 0.46 - 0.98) (Figure 2). In order to evaluate graphically the agreement or discrepancy between the sums of numerical responses given by patients questioned on the same day by two different interviewers, the results of applications of Brazil-MOPDS were plotted in a Bland-Altman Plot (Figure 3).

This enabled us to recognize the magnitude of variation between the responses as well as the existence of systematic bias between the two interviewers. The value of the arithmetic mean was equal to -0.48 (CI $1.08-0.12$ ), showing a strong correlation [15].

Data obtained in the intra-observer correlation in the administration of the questionnaire, also showed an excellent agreement with ICC $=0.982($ CI $0.967-0.997)(P<0.001)$ (Figure 3).

Criterion validity was established by comparing the data of the scale with the results of the OHIP-14, VAS and the three Brazil-MOPDS interviews (Table 4).

The correlation between the scores of BrazilMOPDS and OHIP-14 was high, $r=0.857$ (CI $0.765-0.915)(\mathrm{P}<0.001)$ and the correlation of scores of Brazil-MOPDS with VAS was also strong - $\mathrm{r}=0.758$ (CI 0.615 0.852) $(\mathrm{P}<0.001)$.

Table 1. Sample distribution by gender and age

\begin{tabular}{lcc}
\hline & $\mathbf{N}$ & $\mathbf{\%}$ \\
\hline Gender & 43 & 86 \\
Female & 7 & 14 \\
Male & 50 & 100 \\
\hline Total & 12 & \\
\hline Age (years) & 23 & 24 \\
$18-29$ & 15 & 46 \\
$30-49$ & 30 \\
$40-69$ & $40.7(14.03)$ & \\
\hline Mean (SD)
\end{tabular}

$\mathrm{N}=$ number of participants.

$\mathrm{SD}=$ standard deviation . 
Table 2. Answers distribution by the three interviews

\begin{tabular}{|c|}
\hline Question/Answer \\
\hline Because of pain in my face, jaws or mouths: \\
\hline I cannot open my mouth as wide as I could \\
\hline None of the time \\
\hline On some days \\
\hline On most/everyday(s) \\
\hline I find it difficult to talk for long periods of time \\
\hline None of the time \\
\hline On some days \\
\hline On most/everyday(s) \\
\hline I find it difficulty to smile or laugh \\
\hline None of the time \\
\hline On some days \\
\hline On most/everyday(s) \\
\hline I cannot touch my face \\
\hline None of the time \\
\hline On some days \\
\hline On most/everyday(s) \\
\hline I cannot find a comfortable position in which to sleep \\
\hline None of the time \\
\hline On some days \\
\hline On most/everyday(s) \\
\hline I wake up at night in pain \\
\hline None of the time \\
\hline On some days \\
\hline On most/everyday(s) \\
\hline I have difficulty falling asleep \\
\hline None of the time \\
\hline On some days \\
\hline On most/everyday(s) \\
\hline I cannot eat hard foods like apples or toast \\
\hline None of the time \\
\hline On some days \\
\hline On most/everyday(s) \\
\hline I take longer to finish my meals \\
\hline None of the time \\
\hline On some days \\
\hline On most/everyday(s) \\
\hline I am unable to eat out in restaurants \\
\hline None of the time \\
\hline On some days \\
\hline On most/everyday(s) \\
\hline I no longer enjoy my food \\
\hline None of the time \\
\hline On some days \\
\hline On most/everyday(s) \\
\hline I find it sore to kiss \\
\hline None of the time \\
\hline On some days \\
\hline On most/everyday(s) \\
\hline I have had to take time off work \\
\hline None of the time \\
\hline On some days \\
\hline On most/everyday(s) \\
\hline People find me difficult to live with \\
\hline None of the time \\
\hline On some days \\
\hline On most/everyday(s) \\
\hline I have had to take time off work \\
\hline None of the time \\
\hline On some days \\
\hline On most/everyday(s) \\
\hline I have problems performing normal household tasks \\
\hline None of the time \\
\hline On some days \\
\hline On most/everyday(s) \\
\hline I would rather be by myself \\
\hline None of the time \\
\hline On some days \\
\hline On most/everyday(s) \\
\hline I have cancelled social activities and holidays \\
\hline None of the time \\
\hline On some days \\
\hline On most/everyday(s) \\
\hline I feel weary/tired \\
\hline None of the time \\
\hline On some days \\
\hline On most/everyday(s) \\
\hline I cannot stop crying \\
\hline None of the time \\
\hline On some days \\
\hline On most/everyday(s) \\
\hline I am worried that I may have a serious illness \\
\hline None of the time \\
\hline On some days \\
\hline On most/everyday(s) \\
\hline I feel embarrassed and self conscious \\
\hline None of the time \\
\hline On some days \\
\hline On most/everyday(s) \\
\hline I feel depressed \\
\hline None of the time \\
\hline On some days \\
\hline On most/everyday(s) \\
\hline I feel I no longer take any pleasure in life \\
\hline None of the time \\
\hline On some days \\
\hline On most/everyday(s) \\
\hline
\end{tabular}

$\mathrm{N}=$ number of participants. 
Table 3. Correlation between questions and whole Brazil-MOPDS and Cronbach $\alpha$ if the question were excluded

\begin{tabular}{|c|c|c|}
\hline Because of pain in my face, jaws or mouths & $\begin{array}{l}\text { Correlation between each question } \\
\text { and whole result }\end{array}$ & $\begin{array}{c}\text { Cronbach } \alpha \text { with question } \\
\text { exclusion }\end{array}$ \\
\hline I cannot open my mouth as wide as I could & 0.482 & 0.917 \\
\hline I cannot touch my face & 0.293 & 0.92 \\
\hline I have difficulty falling asleep & 0.659 & 0.913 \\
\hline I wake up at night in pain & 0.746 & 0.911 \\
\hline I cannot find a comfortable position in which to sleep & 0.568 & 0.915 \\
\hline I cannot eat hard foods like apples or toast & 0.526 & 0.916 \\
\hline I take longer to finish my meals & 0.578 & 0.915 \\
\hline I no longer enjoy my food & 0.68 & 0.913 \\
\hline I find it sore to kiss & 0.639 & 0.913 \\
\hline I find it difficulty to smile or laugh & 0.551 & 0.915 \\
\hline People find me difficult to live with & 0.535 & 0.915 \\
\hline I have had to take time off work & 0.446 & 0.917 \\
\hline I have found it difficult to concentrate & 0.559 & 0.915 \\
\hline I have problems performing normal household tasks & 0.577 & 0.914 \\
\hline I would rather be by myself & 0.739 & 0.911 \\
\hline I find it difficult to talk for long periods of time & 0.635 & 0.914 \\
\hline I have cancelled social activities and holidays & 0.615 & 0.914 \\
\hline I am unable to eat out in restaurants & 0.631 & 0.913 \\
\hline I feel weary/tired & 0.654 & 0.913 \\
\hline I cannot stop crying & 0.563 & 0.915 \\
\hline I am worried that I may have a serious illness & 0.374 & 0.919 \\
\hline I feel embarrassed and self conscious & 0.727 & 0.912 \\
\hline I feel depressed & 0.787 & 0.91 \\
\hline I feel I no longer take any pleasure in life & 0.744 & 0.914 \\
\hline
\end{tabular}

aPearson correlation, question-whole result.

Table 4. OHIP-14, VAS and Brazil-MOPDS answers

\begin{tabular}{cccccc}
\hline $\begin{array}{c}\text { Participants } \\
\text { N=50 }\end{array}$ & OHIP-14 & VAS & $\begin{array}{c}\text { Brazil-MOPDS } \\
\text { First interviewer } \\
\text { (1st interview) }\end{array}$ & $\begin{array}{c}\text { Brazil-MOPDS } \\
\text { First interviewer } \\
\text { (2nd interview) }\end{array}$ & $\begin{array}{c}\text { Brazil-MOPDS } \\
\text { Second interviewer }\end{array}$ \\
\hline Mean & 10.28 & 6.67 & 13.66 & 14.14 & 14.12 \\
\hline SD & 6.16 & 2.03 & 9.93 & 10.26 & 10.17 \\
\hline
\end{tabular}

$\mathrm{SD}=$ standard deviation.

\section{DISCUSSION}

We have successfully adapted the MOPDS into the Portuguese language. Not only were we able to translate it, but also validate and culturally adapt it. Previous instruments have not been specifically designed to measure the impact associated with orofacial pain.

Orofacial pain has not only biological but also psychological and social effects on patients [16]. Psychosocial effects are difficult to objectively measure and certainly deserve attention in the evaluation of therapeutic measures for chronic orofacial pain. In fact they may be the only measures to assess patient improvement particularly where there is no underlying pathology to explain reported symptoms [17-21].

Further, indicators of oral health related quality of life are often used to complement clinical data in crosssectional and longitudinal studies [22]. Orofacial pain is a commonly observed symptom of dental disease in Brazil. Borges et al. [23] estimated the prevalence of dental and gingival pain and associated factors 
among 16,126 young Brazilians (15 - 19 years) who participated in the epidemiological survey of Oral Health (2002 - 2003) in Brazil for six months. Through simple and multiple Poisson regression there was a high prevalence of dental and gingival pain: $35.6 \%$ (CI: 34.8 - 36.4). The increased prevalence of pain was associated with female public school students, low income and education gap. Adolescents with high levels of caries and dental calculus also reported a higher prevalence of dental pain.

The successful translation and cross-cultural adaptation of the MOPDS [10], which had its development based on people who had just this specific condition will therefore be extremely valuable to measure the specific effects of orofacial pain in Brazilian populations.

Other questionnaires like GOHAI (Geriatric Oral Health Assessment Index, RDC/TMD, OHIP, McGill pain questionnaire and OIDP have been translated and validated for use in Brazilian researches [24-29]. However, these instruments have not been specifically designed to measure the impact associated with orofacial pain.

Although some English terms do not have equivalent descriptors in Portuguese, trans-cultural adjustments proved to be a valid and efficient alternative to overcome this difficulty, which can be confirmed in the application of the final version of the questionnaire. Adaptation to local culture is essential for a correct evaluation of the process of pain [30].

Therefore the Brazil-MOPDS was obtained from translation and cultural adaptation as performed according to current and internationally accepted guidelines $[11,12]$. It showed excellent reproducibility, validity and practicality application with high Cronbach's Alpha scores, and good correlation co-efficient. The Bland-Altmann test, associated with the ICC was used for providing more information than the use of a test alone. One of the main advantages of this method, in which differences between the scores of the first and second evaluation are plotted on the mean values is to allow the recognition of both the amplitude of variation as to the existence of systematic bias between the two interviews It is necessary at least 50 individuals for the use of this method.
However, our study was conducted on patients referred into a tertiary setting who may represent the most severe and intractable cases of orofacial pain. Further research is needed in establishing the validity of the Brazil-MOPDS in population settings and also its responsiveness as a measurement of treatment outcomes in clinical trials of chronic orofacial pain. We envisage that it will be an important tool for such patients where improvement cannot be assessed in terms of structural improvement (elimination of infection or removal of diseased tissue) as there is no underlying cause for reported symptoms. Rather, measurements of disability before and after treatment may provide important information on treatment outcomes and therefore influence further management of the patient [8].

\section{CONCLUSIONS}

The data showed that the process of translation and cross-cultural adaptation of Manchester Orofacial Pain disability Scale was successful and that Brazil Orofacial Pain disability Scale seems to be a valid and reliable instrument for describing pain-related impact among patients with symptoms of orofacial pain.

\section{ACKNOWLEDGMENTS AND DISCLOSURE STATEMENTS}

The authors are most grateful to the patients for their help with the study. The study was funded by the author and School of Dentistry of University of São Paulo, Brazil. Vishal Aggarwal is funded by a Clinician Scientist Award issued by the NIHR - grant number CS/2008/08/001. The views expressed in this publication are those of the author(s) and not necessarily those of the NHS, the National Institute for Health Research or the Department of Health UK. There are no conflicts of interest to declare. Vishal Aggarwal also has a substantive part-time appointment as a Senior Lecturer in Academic General Dental Practice at Queen Mary's University London, UK.

No external funding, apart from the support of the authors' institution, was available for this study.

\section{REFERENCES}

1. Locker D, Clarke M, Payne B. Self-perceived oral health status, psychological well-being, and life satisfaction in an older adult population. J Dent Res. 2000 Apr;79(4):970-5 [Medline: 10831100] [doi: 10.1177/00220345000790041301]

2. Locker D, Grushka M. Prevalence of oral and facial pain and discomfort: preliminary results of a mail survey. Community Dent Oral Epidemiol. 1987 Jun;15(3):169-72. [Medline: 3474103] [doi: 10.1111/j.1600-0528.1987.tb00508.x]

3. Lund, JP, Lavigne GJ, Dubner R, Sessle B.J. Orofacial Pain: From Basic Science to Clinical Management. Chicago: Quintessence; 2001.p. 300 
4. Macfarlane TV, Glenny AM, Worthington HV. Systematic review of population-base epidemiological studies of orofacial pain. J Dent. 2001 Sep;29(7):451-67. [Medline: 11809323] [doi: 10.1016/S0300-5712(01)00041-0]

5. Katz J, Melzack R. Measurement of pain. Surg Clin North Am. 1999 Apr;79(2):231-52. [Medline: 10352653] [doi: 10.1016/S0039-6109(05)70381-9]

6. Niv D, Kreitler S. Pain and Quality of Life. Pain Pract. 2001 Jun;1(2):150-61. [Medline: 17129291] [doi: $10.1046 / \mathrm{j} .1533-2500.2001 .01016 . x$ ]

7. de Lucena LB, Kosminsky M, da Costa LJ, de Góes PS. Validation of the Portuguese version of the RDC/TMD Axis II questionnaire. BrazOral Res. 2006 Oct-Dec;20(4):312-7. [Medline:17242791] [doi:10.1590/S1806-83242006000400006]

8. Varoli FK, Pedrazzi V. Adapted version of Mcgill questionnarie to brazilian Portuguese. Braz Dent J. 2006;17(4):328-35. [Medline: 17262148] [doi: 10.1590/S0103-64402006000400012]

9. Locker D, Allen F. What do measures of 'oral-health-related quality of life'mesure? Community Dent Oral Epidemiol 2007;35:401-11. [doi: 10.1111/j.1600-0528.2007.00418.x]

10. Aggarwal, V.R.; Lunt, M.; Zakrzewska, J. M.; Macfarlane, G. J.; Macfarlane, T.V. Development and validation of the Manchester Orofacial pain disability scale. Community Dentistry Oral Epidemiology. 2005 Apr;33(2):141-9. [Medline: 15725177] [doi: 10.1111/j.1600-0528.2004.00193.x]

11. Beaton DE, Bombardier C, Guillemin F, Ferraz MB. Guidelines for the process of cross-cultural adaptation of self-report measures. Spine. 2000 Dec 15;24(24):3186-91. [Medline: 11124735] [doi: 10.1097/00007632-200012150-00014]

12. Wild D, Grove A, Martin M, Eremenco S, McElroy S, Verjee-Lorenz A, Erikson P; ISPOR Task Force for Translation and Cultural Adaptation. Principles of Good Practice for the Translation and Cultural Adaptation Process for Patient-Reported Outcomes (PRO) Measures: Report of the ISPOR Task Force for Translation and Cultural Adaptation. Value Health. 2005 Mar-Apr;8(2):94-104. [Medline: 15804318 ] [doi: 10.1111/j.1524-4733.2005.04054.x]

13. Slade GD. Derivation and validation of a short-form oral health impact profile. Community Dent Oral Epidemiol. 1997;25(4):284-90. [Medline: 9332805] [doi: 10.1111/j.1600-0528.1997.tb00941.x]

14. Stata Statistical Software. Stata. (Release 10). 2011. College Station, TX: Stata Corporation. Ref Type: Computer Program.

15. Bland JM, Altman DG. Statistical methods for assessing agreement between two methods of clinical measurement. Lancet, i, 1986 307-310. [doi: 10.1016/S0140-6736(86)90837-8]

16. Brown FF, Robinson ME, Riley JL, Gremillion HA. Pain severity, negative affect, and microstressers as predictors of life interference in TMD patients. Cranio. 1996 Jan;14(1):63-70. [Medline: 9086878 ]

17. Acharya S, Bhat PV, Acharya S. Factors affecting oral health-related quality of life among pregnant women. International Journal of Dental Hygienist. 2009 May;7(2):102-7. [Medline: 19416092] [doi: 10.1111/j.1601-5037.2008.00351.x]

18. Alexandre GC, Nadanovsky P, Lopes CS, Faerstein E. Prevalence and factors associated with dental pain that prevents the performance of routine tasks by civil servants in Rio de Janeiro, Brazil. Cadernos de Saúde Pública, Rio de Janeiro. 2006 May;22(5):1073-8. [Medline 16680360]

19. Carlson CR, Bertrand PM, Ehrlich AD, Maxwell AW, Burton RG. Physical self-regulation training for the management of temporomandibular disorders. Journal of Orofacial Pain. 2001 Winter; 15(1),47-55. [Medline: 11889647]

20. Greene CS. The etiology of temporomandibular disorders: implications for treatment. J Orofac Pain. 2001 Spring;15(2):93-105. [Medline: 11443830]

21. Oliveira AS, Bermudez CC, Souza RA, Souza CM, Dias EM, Castro CE, Bérzin F. Impacto da dor na vida de portadores de disfunções temporomandibular. J Appl Oral Sci. 2003 Jun;11(2):138-143. [Medline: 21409327] [doi: 10.1590/S1678-77572003000200010]

22. Montero-Martín J, Bravo-Pérez M, Albaladejo-Martínez A, Hernández-Martín LA, Rosel-Gallardo EM. Validation the Oral Health Impact Profile (OHIP-14sp) for adults in Spain. Med Oral Patol Oral Cir Bucal. 2009 Jan 1;14(1):E44-50. [Medline: 19114956$]$

23. Borges CM, Cascaes AM, Fischer TK, Boing AF, Peres MA, Peres KG. Dor nos dentes e gengivas e fatores associados em adolescentes brasileiros: análise do inquérito nacional de saúde bucal SB-Brasil 2002-2003. Cadernos de Saúde Pública. 2008 Aug; 24(8):1825-34. [Medline: 18709223] [doi: 10.1590/S0102-311X2008000800011]

24. Cortes MI, Marcenes W, Sheiham A. Impact of traumatic injuries to the permanent teeth on the oral health-related quality of life in 12-14-year-old children. Community Dent Oral Epidemiol. 2002 Jun;30(3):193-8. [Medline: 12000342] [doi: $10.1034 / j .1600-0528.2002 .300305 . x$ ]

25. Abegg C, Gomes AS. The impact of oral health on daily performance of municipal waste disposal workers in Porto Alegre. Cadernos de Saúde Pública, Rio de Janeiro. 2007 Jul;23(7): 1707-14. [Medline: 17572821]

26. Pires CP, Ferraz MB, de Abreu MH. Translation into Brazilian portuguese, cultural adaptation and validation of the oral health impact profile (ohip-49). Braz Oral Res. 2006 Jul-Sep;20(3):263-8. [Medline: 17119711] [doi: 10.1590/S1806-83242006000300015]

27. da Silva SR, Castellanos Fernandes RA. Self perception of oral health status by elderly. Rev Saude Publica. 2001 Aug;35(4):349-55. [Medline: 11600923]

28. Barros Vde M, Seraidarian PI, Côrtes MI, de Paula LV. The impact of Orofacial pain on the quality of life of patients with temporomandibular disorder. Journal of Orofacial Pain. 2009 Winter;23(1):28-37. [Medline: 19264033] 
29. de Oliveira BH, Nadanovsky P. The impact of oral pain on quality of life during pregnancy in low-income Brazilian women. J Orofac Pain. 2006 Fall;20(4):297-305. [Medline: 17190028]

30. Rodrigues MF, Michel-Crosato E, Cardoso JR, Traebert J. Psychometric properties and cross-cultural adaptation of the Brasilian Quebec back pain disability scale questionnaire. Spine (Phila Pa 1976). 2009 Jun 1;34(13):E459-64. [Medline: 19478648$]$

\section{To cite this article:}

Kallás MS, Crosato EM, Maria Biazevic MG, Mori M, Aggarwal VR. Translation and Cross-Cultural Adaptation of the Manchester Orofacial Pain Disability Scale.

J Oral Maxillofac Res 2012;3(4):e3

URL: http://www.ejomr.org/JOMR/archives/2012/4/e3/v3n4e3ht.pdf

doi: $10.5037 /$ jomr.2012.3403

Copyright (C) Kallás MS, Crosato EM, Maria Biazevic MG, Mori M, Aggarwal VR. Accepted for publication in the JOURNAL OF ORAL \& MAXILLOFACIAL RESEARCH (http://www.ejomr.org), 21 August 2012.

This is an open-access article, first published in the JOURNAL OF ORAL \& MAXILLOFACIAL RESEARCH, distributed under the terms of the Creative Commons Attribution-Noncommercial-No Derivative Works 3.0 Unported License, which permits unrestricted non-commercial use, distribution, and reproduction in any medium, provided the original work and is properly cited. The copyright, license information and link to the original publication on (http://www.ejomr.org) must be included. 